\title{
Research
}

\section{Integrating Data, Biology, and Decision Models for Invasive Species Management: Application to Leafy Spurge (Euphorbia esula)}

\author{
$\underline{\text { Ayaz Hyder }}^{1}$, Brian Leung $^{1}$, and Zewei Miao $^{2}$
}

\begin{abstract}
Invasive species are a major cause of environmental change and are often costly to control. Decision theory should offer managers guidance to formulate the optimal allocation of resources. Unfortunately, current decision theory models typically do not consider invasion dynamics and do not make full use of the best models of biological spread and best biological data from theoretical models. We developed a decision theory model that integrated population dynamics, spread, uncertainty, and changes in management policies. We applied this model to leafy spurge (Euphorbia esula), a high-priority invasive weed in North America. We used field data to construct a biological model that included stochastic population dynamics and spatial spread and integrated it with decision theory using stochastic dynamic programming (SDP). The SDP model considered three control strategies: no control, biological control, and herbicide control. Solutions from the SDP model determined the optimal strategy to apply at a given state for any time horizon. The optimal strategy depended on the area and density of leafy spurge and varied with the time horizon; therefore, dynamic control is important in management programs. Biological control was consistently indicated as the optimal strategy for all time horizons. Herbicide control was the optimal strategy for small areas with high-density infestation for long time horizons. We conclude that dynamic control, forecasting, and the time horizon are important considerations for invasive species managers who are under financial, logistical, and time constraints.
\end{abstract}

Key Words: decision theory, leafy spurge, management, stochastic dynamic programming

\section{INTRODUCTION}

Invasive species present a complex and dynamic problem for ecosystems and society. Here, we use the term invasive to specify nonindigenous species that arrive and establish at a new geographic location and cause significant damage to indigenous species. The costs of invasive species are twofold: ecological and economic. Invasive species lead to decreased biodiversity (Vitousek et al. 1996). They alter ecosystem (Mack et al. 2000, Sakai et al. 2001, Shea and Chesson 2002), genetic (Grapputo et al. 2005), and evolutionary processes (Sakai et al. 2001, Hoffmeister et al. 2005). The annual economic burden of invasive species eradication and control is > U.S. $\$ 137$ billion in the United States (Pimentel et al. 2000) and ranges from Can. $\$ 13$ to $\$ 34$ billion in Canada (Colautti et al. 2006).

Given the costliness of invasive species, it is imperative to study them and implement the best management decisions and policies. Decision theory is a branch of research that provides formal frameworks with which to make optimal decisions using explicit criteria, often based on the costs and benefits associated with each action. Decision theory tools are used in a variety of areas, including fire control (McCarthy et al. 2001), macroparasite infection (Fenton and Rands 2004), and species distributions (Raimundo et al. 2007), yet they have rarely been applied to invasive species management. This omission might be because of the difficulties of including key processes involved in invasion biology. Although it is not possible to consider all of the details in nature, certain fundamental processes that underly invasions should form the biological basis of management decisions. Simply put, nonindigenous species are usually problematic and costly when their populations grow out of control and when they spread to a large spatial extent. As well, uncertainty exists in management decisions as environmental 
stochasticity; management decisions are based on expected future outcomes that ultimately depend on current and future environmental conditions. Thus, management decisions should be dynamic and incorporate the fact that if control is effective, the environment should change; as the environment changes, so too should control efforts.

Few studies have considered these components of invasion, i.e., population dynamics, spread, uncertainty, and temporal changes in management policies, in an integrated manner with decision theory, but several have considered individual components (Pandey and Medd 1991, Shea and Possingham 2000, Leung et al. 2002, Taylor and Hastings 2004). There are several possible reasons for the lack of integrated studies. First, population dynamics and spread may be measured at different spatial scales, so linking the two with management might require the construction of submodels. Second, data may often exist in a form that is inappropriate for integration into bioeconomic models. Lastly, the inclusion of environmental stochasticity may require more complex models and increase the computational burden. Nevertheless, given that these components are central to processes of invasion, they should be built into decision models.

Here, we introduce theoretical advances in the application of decision theory models to biological problems. Putative methods of decision theory have been brought forth in the invasion literature specifically and in conservation ecology in general. One such method is stochastic dynamic programming (SDP). Researchers are beginning to present decision theoretic and bioeconomic models in applications with invasive species (Leung et al. 2002, Taylor and Hastings 2004), and putative approaches such as SDP are being put forward (Pandey and Medd 1991, Shea and Possingham 2000). SDP explicitly incorporates uncertainty and allows dynamic management decisions in its forecasting of future environmental conditions and future optimal policies. SDP is flexible enough to incorporate ecology, management, and economics (Leung et al. 2002). In SDP, the optimal decision is based on the current state of the system; a state can represent ecological properties of the system such as spread and population size, and by extension, spatial and population dynamics, which dictate movement between states. Thus, SDP should be useful to build integrative decision models for biological invasions.
We used leafy spurge (Euphorbia esula) as a case study. We think that the application of models to real-world systems makes theoretical developments more compelling, ensures that theory considers constraints and challenges associated with real data, and is useful to address current environmental issues. We used leafy spurge because it is a major pest that is widespread largely in the United States and Canada (http://www.team.ars.usda.gov/images/ lsdistnox.jpg). Leafy spurge is an exotic, perennial weed. Its aggressive and rapid spread is attributed to a deep root system, an early and rapid growth phase, and prolonged seed viability of up to $8 \mathrm{yr}$ (Foley 2004). Leafy spurge was first reported in North America in 1827. Its range today extends from southwest Ontario and northeast United States to the Canadian prairie provinces, central United States, and California (White et al. 1993). The problem is most troublesome in the Great Plains region of the United States. Leafy spurge is the most costly and damaging weed in North Dakota, from where our empirical data were obtained (North Dakota Department of Agriculture 2005). Currently, leafy spurge is controlled using biological control agents, herbicides, multispecies grazing, or a combination of these three strategies. Each control strategy has its own trade-offs in terms of cost and efficacy, making leafy spurge an ideal model system for decision theory.

Decision theoretic approaches such as SDP potentially have important contributions for invasion biology. However, there is typically a lack of integration between biology and decision theory whereby only a few simplified environmental states are considered. Ideally, the best of decision theory and biological models should be used. The integration of modeling approaches from various disciplines, although difficult, is necessary if these decision theory models are ever to be used outside of a pure academic arena. Additionally, in biology, simulation models are often simplified by assuming parameter values such as dispersal parameters from data that have been collected in experiments or other systems (Nehrbass et al. 2006, Pausas et al. 2006). Alternatively, the observed pattern of interest, i.e., the spatial spread of leafy spurge, could be used directly to parameterize the model. Recent publications have highlighted the rarity and argued for the use of this alternative approach to infer parameters directly from patterns in plant biology (Winkler and Heinken 2007). We used this approach to demonstrate its utility for invasion biology. 
We developed a methodology for the integration of SDP with a spatially explicit model of population spread that represents the best descriptor of spread and population dynamics that is available. Further, we incorporated time lags in the effectiveness of control methods, which is an important concept in invasion biology, but is not common in SDP. We developed these techniques with the consideration of real-world data. To take advantage of real-world data, we developed a biological submodel to directly parameterize the observed pattern of interest: the spatial spread of leafy spurge. We applied our approach to the case of leafy spurge to demonstrate the application of SDP in answering the following questions: Which strategy is optimal? How does the optimal strategy change with the state of the environment, e.g., density and spatial extent of leafy spurge? How does the time frame, i.e., short-term vs. long-term control, affect economic gains?

\section{METHODS}

\section{Biological model for leafy spurge (Euphorbia esula)}

We constructed a biological model based on empirical data on the spread and population dynamics of leafy spurge obtained from the literature. Data were collected from economic reports to determine the spatial extent of leafy spurge in North Dakota (Table 1). For population dynamics, we used Selleck et al.'s (1962) empirical data on density (Table 2) to parameterize a logistic growth model of the form

$$
N_{t+1}=N_{t}+r N_{t}\left(1-\frac{N_{t}}{K}\right)
$$

where $N_{\mathrm{t}+1}$ and $N_{\mathrm{t}}$ are the density of leafy spurge in stems per square meter at time $t+1$ and time $t$, respectively; $r$ is the intrinsic growth rate of leafy spurge; and $K$ is the carrying capacity of the environment.

Selleck et al. (1962) reported density in shoots per square meter, but we assumed this to be equivalent to stems per square meter because both units indicate the presence of a leafy spurge individual, which is sufficient for the biological model. To determine the values of $r$ and $K$, we took the derivative of eq. 1 as

$$
\Delta N=N_{t+1}-N_{t}=r N_{t}-\frac{r}{K} N_{t}^{2}
$$

We calculated $\Delta N$ and $N_{\mathrm{t}}$ from the empirical data using a quadratic polynomial with an intercept of zero. We determined the best fitting parameters for the polynomial function and derived the values of 0.4791 and 218 for $r$ and $K$, respectively. We set $N_{0}=19.1$ for the fitting procedure because leafy spurge is unlikely to be completely eradicated in the field (Harris et al. 1985, Lajuenesse et al. 1994) and this was the lowest value reported in the literature (Selleck et al. 1962). We then explicitly incorporated the above information on spread and population dynamics into a model of spatial spread for leafy spurge.

We used coupled map lattices (CMLs) to build a model of spatial spread that incorporates essential invasion biology components such as population dynamics and stochasticity. In CML modeling, processes occur within and over grid cells, and model fitting is computationally intensive because of the number of parameters to be estimated and the parameter space. Therefore, we set the grid size of our CML model to $2000 \times 2000$ cells, where each cell represented an area of 9 ha. This grid size was $>10$ times larger than the extent of the actual invasion, such that the bounds of the grid were never reached in the simulations and we could entirely avoid the problem of boundary effects.

We based the biological model on a simple invasion process with stages of dispersal and establishment. One cell was initially infested at the beginning of the simulation, after which growth occurred according to eq. 1 , followed by dispersal. Dispersal was characterized by a probabilistic dispersal kernel. We calculated the number of propagules (seeds) that arrived at uninfested cells as a propagule's probability of dispersal from an infested cell to an uninfested cell multiplied by the number of propagules in the infested cell: 
Table 1. Spread of leafy spurge in North Dakota, USA.

\begin{tabular}{lcc}
\hline \hline Year & Time $(\mathrm{yr})$ & Infested area (ha) \\
\hline 1909 & $0 \ddagger$ & 0 \\
1962 & 53 & 80900.00 \\
1973 & 64 & 171400.00 \\
1982 & 73 & 348800.00 \\
1987 & 78 & 404685.64 \\
1990 & 81 & 526091.33 \\
\hline
\end{tabular}

Note: Data were obtained from Leistritz et al. (1992), Lym et al. (1993), Leitch et al. (1994), and Bangsund et al. (1997).

$\ddagger$ Time since leafy spurge is thought to have entered North Dakota rangeland.

$$
N_{\mathrm{u}, \mathrm{t}}=\sum_{\mathrm{i}=1}^{\mathrm{n}}\left(N_{\mathrm{i}, \mathrm{t}} * \mathcal{k}_{\mathrm{i} \rightarrow \mathrm{u}}\right)
$$

where $N_{\mathrm{u}, \mathrm{t}}$ is the number of propagules that reach an uninfested cell $u, N_{\mathrm{i}, \mathrm{t}}$ is the number of propagules generated by infested cell $i$ at time $t$, and $p_{\mathrm{i}} \rightarrow \mathrm{u}$ is the probability of propagules reaching cell $u$ from cell $i$.

Infested cells near an uninfested cell contribute seeds; thus, we summed the number of propagules coming from $n$ infested cells that were within a critical distance of $L$ cells away. The negative exponential dispersal kernel has been widely used to approximate seed dispersal in other models (He and Mladenoff 1999, Ellison and Parker 2002). Dispersal kernels in ecology incorporate vectors such as wind, animals, and humans, in addition to seeds simply dropping around a plant. As well, dispersal is not only limited to movement, but incorporates seasonality, time, and other processes that are not known to the modelers of a system. Therefore, the use of the negative exponential kernel is justified for our model. We calculated the critical distance $L$ from the probability density function PDF of the dispersal kernel as follows:

$$
\mathrm{PDF}=a e^{-\alpha x}
$$

Using the cumulative probability function, the following equations can be formulated:

$$
p=\frac{\int_{0}^{L} e^{-p x} d x}{\int_{0}^{\infty} e^{-p x} d x}=a
$$

and

$$
p=\frac{\left.(-1 / \beta) e^{-\beta x}\right|_{0} ^{L}}{(-1 / \beta)}=a
$$

where $p$ is the cumulative probability of propagule dispersal up to distance $L, a$ is the intercept of the 
Table 2. Changes in the density of leafy spurge (shoots $/ \mathrm{m}^{2}$ ) during 1951-1957 according to the intial density (Selleck et al. 1962).

\begin{tabular}{|c|c|c|c|c|c|c|c|c|}
\hline \multirow[t]{2}{*}{ Initial density } & \multicolumn{7}{|c|}{ Year } & \multirow[t]{2}{*}{ Mean density } \\
\hline & 1951 & 1952 & 1953 & 1954 & 1955 & 1956 & 1957 & \\
\hline $1-35$ shoots $/ \mathrm{m}^{2}$ in 1951 & 19.1 & 38.0 & 56.9 & 69.4 & 109.3 & 121.2 & 144.2 & 79.7 \\
\hline $36-99$ shoots/m² in 1951 & 61.5 & 84.5 & 102.0 & 112.0 & 162.9 & 179.9 & 199.4 & 128.9 \\
\hline$\geq 100$ shoots $/ \mathrm{m}^{2}$ in 1951 & 122.5 & 125.5 & 141.3 & 156.7 & 202.8 & 241.6 & 207.7 & 171.1 \\
\hline
\end{tabular}

Note: The study site was divided into quadrats that were classified according to the intial density, and the density was determined annually for each density class.

probability density, $\beta$ is the dispersal coefficient, and $x$ is the distance between two cells.

Solving eq. 6 results in

$$
L=\ln (1-\alpha) /(-\beta)
$$

We solved for $L$ by setting $a=0.9995$, which means that $99.95 \%$ of the propagules are dispersed by the kernel up to distance $L$ from the source. The combination of $L$ and the fitted parameters $\alpha$ and $\beta$ from eq. 7 determined the pattern of spread; one parameter could compensate for the other to generate a similar pattern of invasion. Thus, we chose a value of $L$ that incorporated the majority of the dispersal kernel $(99.95 \%)$ while remaining computationally feasible.

The term $p_{\mathrm{i} \rightarrow \mathrm{u}}$ in eq. 3 , i.e., the probability of dispersal from infested cell $i$ to uninfested cell $u$, is determined as

$$
p_{i \rightarrow u}=\frac{\int_{u}^{u+1} e^{-\beta x} d x}{\int_{-L}^{L} e^{-\mathcal{A} x} d x}
$$

The establishment of leafy spurge was considered to be a probabilistic process because of variable environmental and ecological conditions in nature. We used a modified version of the Weibull distribution (Dennis 2002, Leung et al. 2004) to determine the probability of establishment:

$$
E\left(N_{u, t}\right)=1-e^{-\alpha N_{u, t}}
$$

where $\alpha$ is a scalar for propagule pressure, and $c$ is a shape coefficient. We chose this form because it incorporates propagule pressure $\alpha$ and indicates an Allee effect if $c>1$.

The arrival of propagules within a cell was stochastic and depended on several environmental and biological conditions in nature. We included stochasticity in the invasion process by drawing a 
random number $R$ such that $0 \leq R \leq 1$ and comparing it with $E\left(N_{\mathrm{u}, t}\right)$; establishment occurs if $E\left(N_{\mathrm{u}, \mathrm{t}}\right)>R$. We also assumed that once leafy spurge established within a cell, additional dispersal into the cell was negligible, i.e., the population dynamics of the infested area were dominated by local population growth, rather than seed dispersal from other cells. Therefore, a cell in which leafy spurge has established becomes a source of propagules that are capable of invading other cells in which leafy spurge has not yet become established. We parameterized the unknown variables $\alpha, \beta$, and $c$ in eqs. 7 and 9 via a grid search algorithm using an absolute difference fit statistic:

$$
M(\alpha, \beta, c)=\sum_{n=1}^{5}\left|O_{n}-E_{n}\right|
$$

where $M(\alpha, \beta, \mathrm{c})$ is the measure of model fit generated using a given set of values for $\alpha, \beta$, and $c ; O_{\mathrm{n}}$ is the total observed infested area over the 81 yr for which we had data; and $E_{\mathrm{n}}$ is the expected infested area from the field data (Table 1).

From eq. 7, we determined that $\beta>2$ resulted in biologically impossible critical dispersal distance $L$. Hence, the algorithm was set to search for values of $\beta$ between 0 and 2 . Similarly, the initial values of $\beta$ and $c$ were chosen such that the algorithm was computationally feasible. After determining the best fitting parameters, we used them to calculate the critical distance $L$ and generated simulated trajectories to be used by the decision theory model.

\section{Control strategies and stochastic dynamic programming formulation}

The goal of our decision theory model was to provide optimal strategies for any given area and density of leafy spurge infestation. We integrated the results of the biological model for spatial spread into the decision theory model. We describe the stochastic dynamic programming (SDP) model using the terminology of Leung et al. (2002). The main components of the SDP method are states, strategies, and a welfare function that is analogous to the objective function in other publications. States in SDP define the system; in our model, they were the area and density of leafy spurge. We used density as a state to describe the system because it correlates well with leafy spurge cover (Scheiman et al. 2003) and provides an intuitive way to describe the leafy spurge system in terms of management and the effect of control strategies, for which data exist (i. e., the effect of control is to reduce density). Our system consisted of 120 area states and 19 density states, resulting in a total of 4180 possible states for the entire system (Appendix 1). Movement between states is governed by transition matrices that are strategy dependent. We considered three control strategies for leafy spurge: no control, biological control, and herbicide control. Biological control involves the release of the flea beetle Apthona nigriscutis (other species of Apthona are also used by managers) over the infested area. The effectiveness of biological control, in terms of the percentage of leafy spurge controlled, increased over time and peaked after 3-5 yr of application (United States Department of AgricultureAgricultural Research Service TEAM Leafy Spurge 2002). To incorporate this time lag in the effectiveness of biological control, we constructed a transition matrix for $4 \mathrm{yr}$ of biological control (Appendix 1). Herbicide control involves the spraying of infested areas with Picolarm and 2,4-D. Other chemicals are also applied to leafy spurge, but we used the most widely applied ones that were mentioned in the literature. We estimated the percentage control of leafy spurge density for the biological control and herbicide control strategies by averaging the percentages of values from several field experiments (Table 3). We also assumed in the model that the response of grass to management was linearly related to the effect of management on leafy spurge area and density (Kirby et al. 2000, Rinella and Sheley 2005).

The SDP method maximizes a welfare function that is state dependent. For a given area $a$ and density $d$ of leafy spurge infestation, which defines a state $i$, the welfare function is

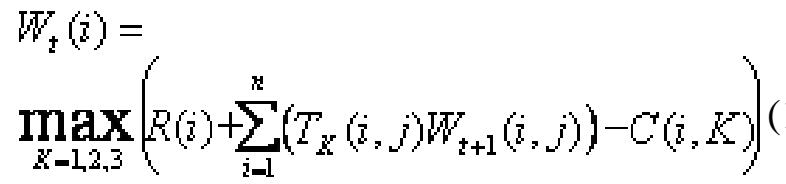

where $W_{\mathrm{t}}(i)$ and $W_{\mathrm{t}+1}(i)$ are the welfare for state $i$ at times $t$ and $t+1$, respectively; $K$ is the index of the strategy applied, where $1=$ no control, $2=$ biological 
Table 3. Control of leafy spurge density using biological control and herbicide control strategies.

\begin{tabular}{lccc}
\hline \hline Strategy & Years of control & $\begin{array}{c}\text { Decrease in leafy spurge density } \\
(\%)\end{array}$ & Data source \\
\hline & 1 & 67 & $\begin{array}{c}\text { McClay et al. (1995), Stromme et al. (1996), } \\
\text { Lym and Nelson (2000), Kirby et al. (2000), } \\
\text { Lym and Nelson (2002), Lym (2005) } \dagger\end{array}$ \\
Biological control & 2 & 76 & \\
& 3 & 81 & Lym and Nelson 2002 $\ddagger$ \\
\hline
\end{tabular}

$\dagger$ The mean percent control was calculated by combining all data sources and attempting to ensure that the experimental conditions were similar.

$\$$ The chemicals and quantities used were Picolarm at $0.56 \mathrm{~kg} / \mathrm{ha}$ and 2,4-D at $1.1 \mathrm{~kg} / \mathrm{ha}$, applied in the fall.

control, and $3=$ herbicide control; $R(i)$ is the net revenue from North Dakota rangeland for state $i$ (Appendix 1); $T_{\mathrm{K}}$ is the probability transition matrix for strategy $K$ to change from state $i$ to $j ; n$ is the total number of future states for current state $i$ that have nonzero probability; and $C(i, K)$ is the cost of using strategy $K$ for state $i$ (Appendix 1).

The welfare function calculated the net revenue at time $t$ by applying control strategy $K$. The SDP model functioned via backward optimization from the time horizon $T$ to $t=0$. It was backward in the sense that the welfare at time $t+1$ was already maximized when it was used to calculate the welfare at time $t$. In SDP, the time horizon is the time frame of interest or the duration in which the consequences of management actions are considered. SDP solutions for long-term control programs were modeled by considering lengthy time horizons up to $T_{\max }=81 \mathrm{yr}$, which was the number of years for which we had data from North Dakota (Table 1). More details about the SDP model are provided in Appendix 1.

To visualize the results of the SDP model, SDP solutions are displayed in state-space graphs for different time horizons and for the difference in welfare between the optimal strategy and only a single strategy for all $t$. In the state-space graphs, each panel shows the optimal strategy identified by SDP for each state (a density and area combination). We used three panels to show different time horizons to illustrate the effect of time frame in determining the optimal strategy, i.e., they illustrate the recommended actions at a particular time for each environmental condition. Although we only show the results for three times, the SDP approach actually generates a panel for each time. Thus, a manager would know which strategy to apply for all times and environmental states. We use a differences graph to show a more intuitive and informative picture of the SDP model by placing the results in terms of economics.

\section{RESULTS}

We used field data on the spread of leafy spurge to fit the coupled map lattice (CML) model using a grid-search algorithm (Table 4). The best fitting model parameters indicated no Allee effect $(c<1)$, and the critical distance $L$ was 28 cells or $8.4 \mathrm{~km}$. Therefore, $99.95 \%$ of propagules were distributed within this distance with an exponentially decreasing probability as the distance from the source cell increased. 
The average simulated trajectory from the CML model fit the field data well (Fig. 1). A lag phase was observed in the simulated trajectory, followed by exponential growth after $40 \mathrm{yr}$. The range of simulated trajectories increased over time, but well encompassed the actual data from the literature.

Using the CML model, we constructed the stochastic dynamic programming (SDP) model to determine the optimal control strategy for leafy spurge. We obtained optimal control strategies for the state space at different time horizons using the SDP model (Fig. 2). We examined the optimal strategy to apply in the first year of management given the current state of the system (i.e., area and density of leafy spurge) to maximize the revenue at time horizon $T$. At short time horizons, biological control was the optimal strategy for all states, except area states with low density. In a low-density state, the no-control strategy was optimal, regardless of the area of leafy spurge infestation. At longer time horizons, biological control was the optimal strategy for small areas of leafy spurge with low density. Herbicide control increasingly became the optimal strategy for areas $<2.0 \times 10^{5}$ ha and densities $>65$ stems $/ \mathrm{m}^{2}$ as the time horizon increased.

The difference in welfare between the optimal strategy and the use of only a single strategy was clearly in favor of the optimal strategy (Fig. 3). For a small area and low-density state, the difference in welfare was highest for the no-control strategy and lowest for the biological control strategy. In contrast, for a larger area and high-density state, herbicide control was the most expensive strategy, whereas biological control remained the least costly compared to the optimal strategy.

\section{DISCUSSION}

An optimal management program for the costly invasive species leafy spurge was determined by integrating available empirical data with biological models in a decision theory framework. Typically, there is a gulf between theory and management decisions. Decision theory is often examined using models that do not fully make use of empirical data, and the applicability of these models to real systems remains unknown. In contrast, current control recommendations for leafy spurge are based on empirical data and do not take advantage of the body of work on decision theory. Few researchers and managers have used theory and experimental data to construct models to guide management decisions. We integrated population dynamics, spread, uncertainty, and temporal changes in management policies to develop a more complete decision theory model than currently in use.

Such integration has been rare for invasive species (but see Taylor and Hastings 2004), and more case studies are needed to define the challenges and solutions for the management of invasive species. Integrative models should be developed using a variety of approaches, and the management tool box should be expanded to allow the comparison of pros and cons, as well as the results of models. For instance, Taylor and Hastings (2004) made decisions using genetic algorithms. However, there are other decision theory techniques available such as optimal control theory (Shastri and Diwekar 2006) and stochastic dynamic programming (SDP; Shea and Possingham 2000, Fenton et al. 2002). Genetic algorithms are very flexible, but techniques such as SDP allow the determination of global optima, as well as the development of a full decision matrix for all possible states over time. Therefore, SDP allows dynamic management decisions based on future expectations and allows the analysis of the role that time horizons play in management decisions. Previously, researchers have applied SDP models to biological control (Shea and Possingham 2000, Fenton et al. 2002) and herbicide control (Pandey and Medd 1991, Sells 1995) and have generated insightful heuristics. However, these models mostly relied on theoretical data; therefore, the ability to extend these models to real systems remains unknown. Leung et al. (2002) used SDP in conjunction with empirical data, but only considered management at small scales, rather than regional spread, which is often of interest for invasive species. As well, Taylor and Hastings (2004) recommended applying their methodology at a regional scale. We have demonstrated that it is possible to integrate decision theory using SDP with empirical data and biological models that contain the most relevant components of invasion biology: population and spatial dynamics, uncertainty, and alternative management strategies.

We highlight three key observations from the statespace graphs (Fig. 2) and discuss their biological and management significance. First, we observed that the optimal strategy in state space was dependent on the state and time horizon. This 
Table 4. Initial and best fitting values of parameters for the coupled map lattice model.

\begin{tabular}{lcccc}
\hline \hline Parameter & \multicolumn{3}{c}{ Initial value } & \multirow{2}{*}{ Best fit value } \\
\cline { 2 - 4 } & Start & End & Increase & \\
\hline Dispersal coefficient $(\beta)$ & 0.010000 & 2.00 & 0.010 & 0.090000 \\
Propagule pressure coefficient $(\alpha)$ & 0.001005 & 10.00 & 0.001 & 0.003005 \\
Allee effect coefficient $(c)$ & 0.000000 & 10.00 & 0.500 & 0.500000 \\
\hline
\end{tabular}

dependence points to the importance of dynamic control. Dynamic control occurs when optimal strategies differ in different years of the control program and is especially relevant to consider when previous decisions affect future states, i.e., environmental conditions change after applying a strategy such that a different strategy may be optimal in the next time period. Second, the importance of including essential components of the invasion process was highlighted by including dynamic growth in the biological simulation. We further contend that excluding density as a state variable in the SDP model would have provided limited and suboptimal recommendations for managers. Third, the herbicide control strategy was optimal for more states at longer time horizons than at shorter time horizons. The application of herbicides to densely infested patches resulted in reduced rates of spread because density was related to propagule pressure, which in turn was related to the probability of establishment. At longer time horizons, the lost revenue caused by the larger spatial extent of leafy spurge accumulated over time such that an initial higher investment in control was worthwhile: The benefits of having greater control outweighed the higher costs of herbicide control. At lower density states, this was no longer the case, and the marginal reduction in density was not worthwhile. It is also meaningful to note that despite the time lag in the effectiveness of the biological control strategy, it remained the most frequently applicable optimal strategy at all time horizons. Biological control costs less to apply than does herbicide control and has similar effectiveness after the lag phase. Therefore, a trade-off between cost and effectiveness occurs such that the benefits of applying biological control accumulate quickly.
This is one of the benefits of decision theory models such as SDP: these costs and benefits over time can be examined rigorously. In economic terms, the expected savings from applying the optimal strategy were accumulated faster for larger area and higher density states than for smaller area and lower density states (Fig. 3). This was probably because of the initial welfare, which would have been higher for the large-area and high-density states and much lower for the small-area and low-density states. The smallest difference in welfare among all strategies occurred between the optimal strategy and the biological control strategy (Fig. 3). This corresponds with the conclusions from the statespace graphs (Fig. 2) in which the optimal strategy for most environmental states was biological control. Herbicide control was likely the most expensive strategy for the large-area and highdensity state because it was the costliest of the three strategies considered. Overall, our results point to some generalizations about important concepts in the management of invasive species.

The ability to forecast future costs and resources, as well as management outcomes, is useful and highly regarded in any management plan. It is likely that a biological model based on real data should further increase the reliability of management plans. Our forecasted SDP solution incorporated components of population dynamics, space, and economic costs of two widely used control strategies for leafy spurge. In long-term forecasting, each of these components was important to consider because of their strong interdependency in predicting the spread of leafy spurge. Time horizons were ultimately important for many reasons, but mainly because managers must plan ahead to allocate 
Fig. 1. Actual and simulated spread of leafy spurge in North Dakota rangeland over $81 \mathrm{yr}$. The simulated data are based on the mean of 100 simulations from the coupled map lattice model. The actual data are based on field measurements (see Table 1).

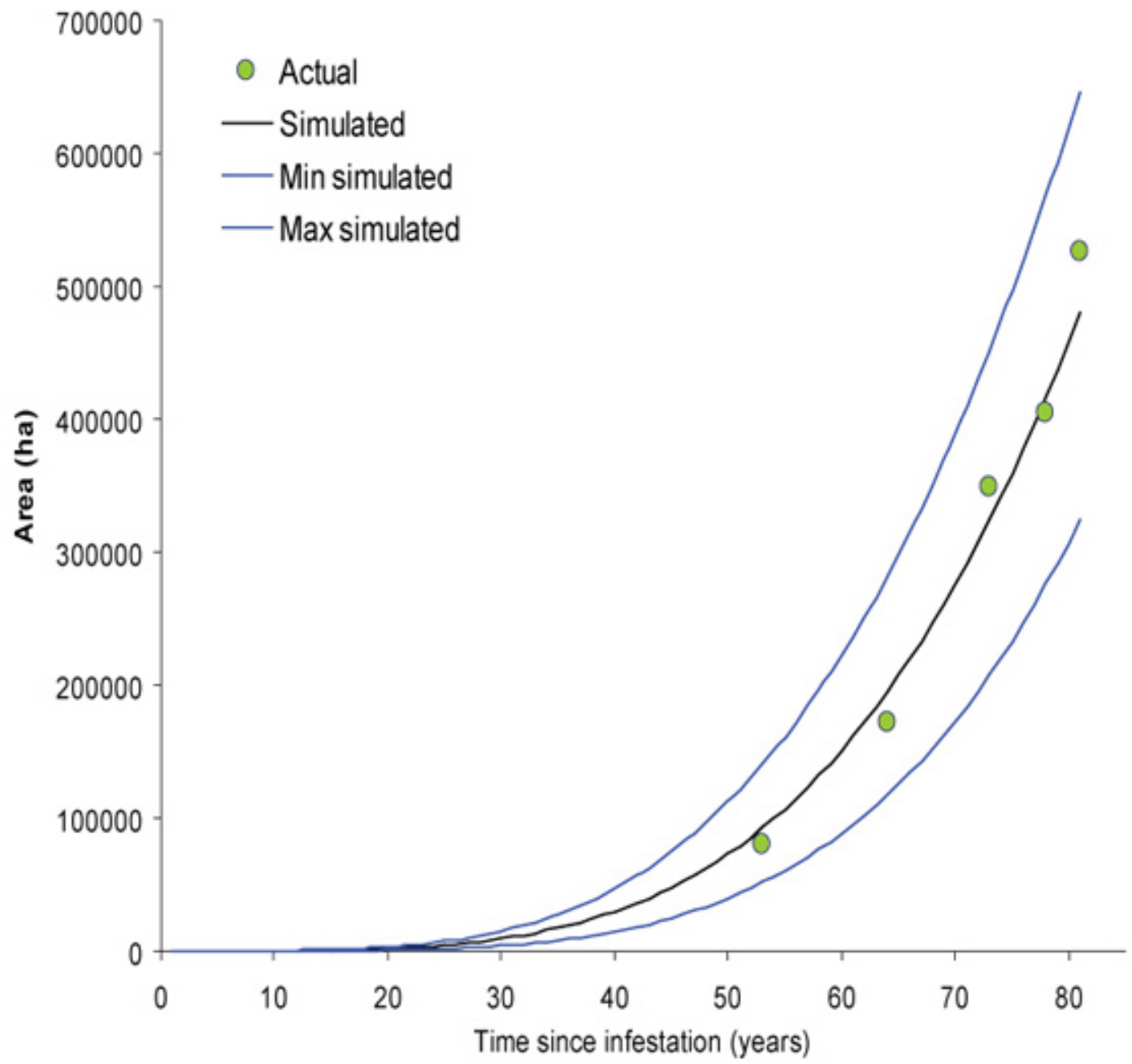

optimally resources from limited budgets. Although managers typically operate on short time horizons and small spatial scales, we argue that such decisions should be examined explicitly to identify their possible consequences. By examining time horizons, we were able to compare different scenarios of control such as 5-10 yr of control vs. a multidecade management plan. The time horizon influenced the optimal strategy for some environmental states, but not others. Our biological spread model indicates that coordination and largescale management plans should be considered, given that invasion dynamics in new areas over time are dependent on whether invaders are present in other areas. As well, improved decision theory models in which environment, economics, and management are linked would be of interest to the various stakeholders involved in invasive species management.

\section{Future considerations}

In our model, we assume that the area of infestation is a homogenous entity, whereas leafy spurge displays patchy growth. It is difficult to build 
Fig. 2. The optimal control strategy to be applied for a given state (area of infestation in hectares) and density (stems of leafy spurge per square meter) using the stochastic dynamic programming solutions for three time horizons. The time horizons were selected to demonstrate the appearance of herbicide control as an optimal strategy at long time horizons.
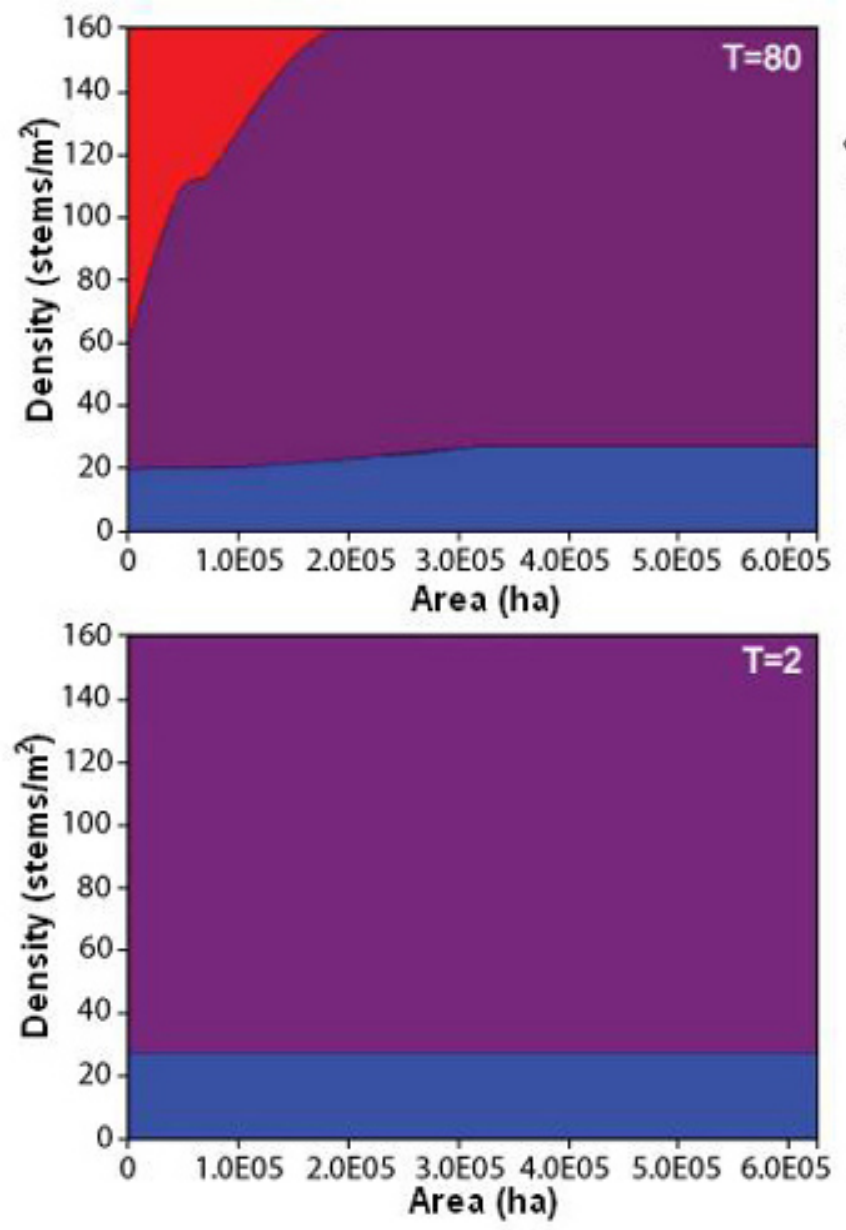

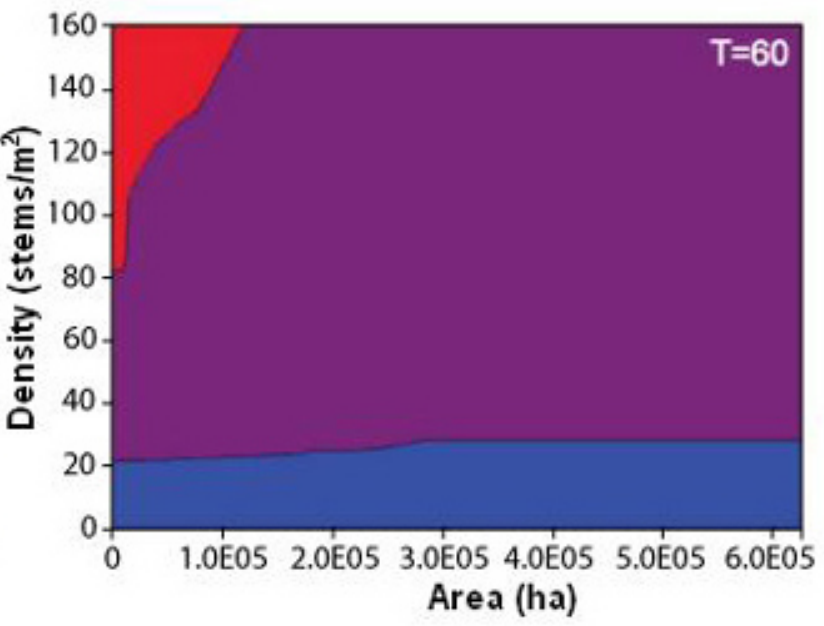

No control

Biological control

$\square$ Herbicide control models that incorporate patchy growth and landscape structure to derive information for decision theory. The difficulties include the formulation of the biological model and computational limitations caused by the complexity of modeling heterogeneity in such a system. For the percentage control of leafy spurge under each control strategy, we used the average of values obtained from several studies and assumed that herbicides were applied in the fall. These generalizations may not be applicable to all infestations of leafy spurge because of differences in soil type, habitat suitability for flea beetles, and restrictions on herbicide usage. Regardless, the general trends observed in our model should still be applicable to most areas of the United States and Canada where leafy spurge occurs.

Future extensions to our model could include the consideration of alternative control strategies and the comparison of results from different decision theory models. Although the examination of biological and herbicide control strategies was sufficient for our purpose of developing a methodology to integrate decision theory and biological spread models, other potential control 
Fig. 3. Difference in welfare for the application of the optimal strategy versus the application of only one strategy (no control, biological control, or herbicide control). The cumulative welfare difference over time starting from a state with (A) a small area and low density and (B) a large area and high density of infestation.

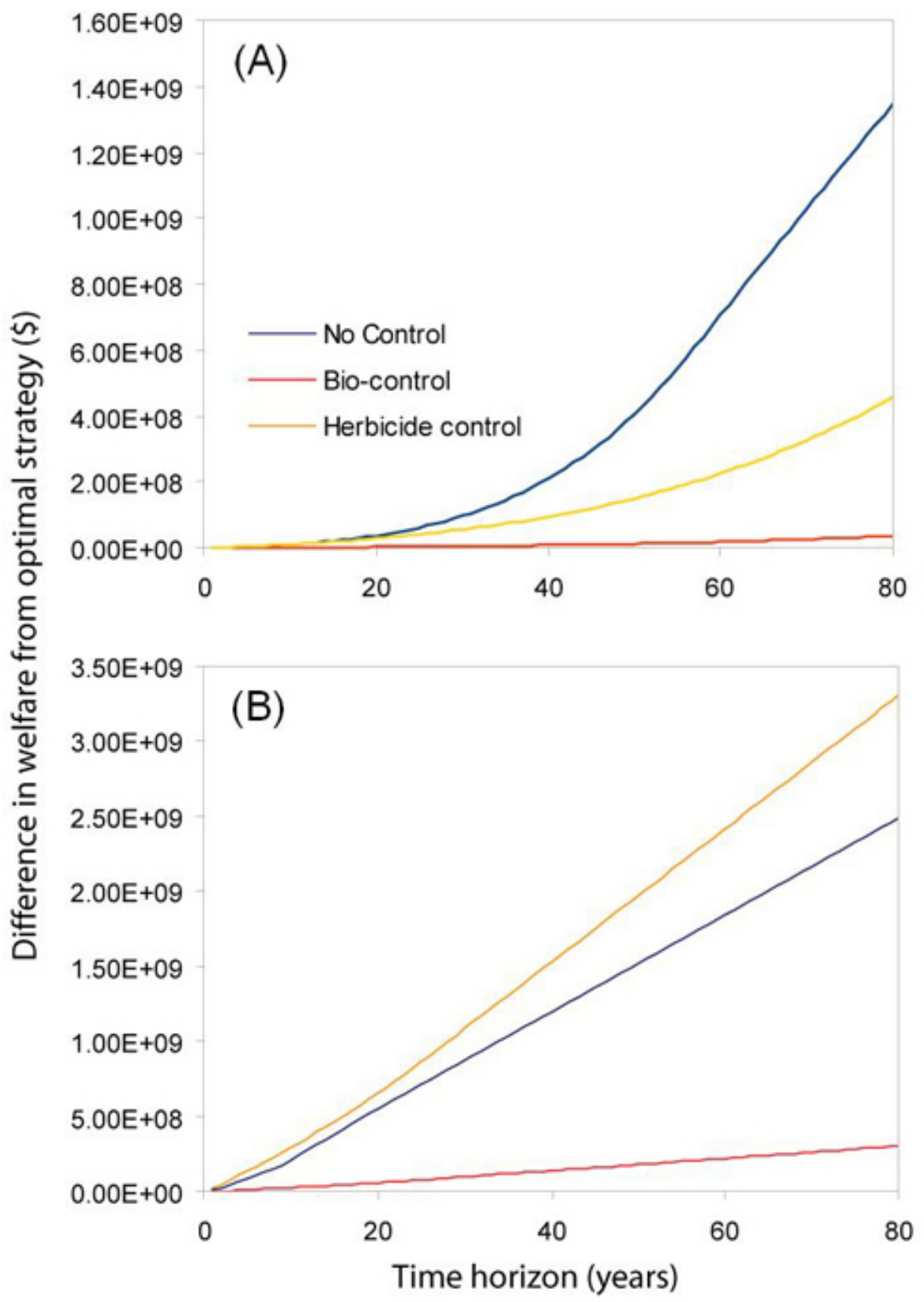


strategies such as sheep grazing and integrated pest management (Lym 2005) may also be worth considering. Similarly, an explicit comparison of the pros and cons of different decision theory frameworks has rarely been done for ecological issues and would be worth exploring. Control theory, genetic algorithms, and neural networks are some other decision theory approaches to consider. Future directions may include the application of our techniques to other invasive species, with modifications in the biological and decision models as required. Regardless of future improvements, our results add to the literature by presenting a methodology for integrating biological models based on empirical data with decision theory, which can then be applied to a to a real-world problem in a management context and provide recommendations based on the model.

Responses to this article can be read online at:

http://www.ecologyandsociety.org/voll3/iss2/art12/responses/

\section{LITERATURE CITED}

Bangsund, D. A., F. L. Leistritz, and J. A. Leitch. 1997. Predicted future economic impacts of biological control of leafy spurge in the upper Midwest. Agricultural Economics Report 382. Agricultural Experiment Station, North Dakota State University, Fargo, North Dakota, USA. Available online at: http://ageconsearch.umn.edu/b itstream/23130/1/aer382.pdf.

Colautti, R. I., S. A. Bailey, C. D. A. van Overdijk, K. Amundsen, and H. J. MacIsaac. 2006. Characterised and projected costs of nonindigenous species in Canada. Biological Invasions 8(1):45-59.

Colorado Natural Areas Program. 2000. Creating an integrated weed management plan: a handbook for owners and managers of lands with natural values. Colorado Department of Natural Resources, Denver, Colorado, USA. Available online at: http:/ /parks.state.co.us/NR/rdonlyres/E4FAAC68-00B4-44A8A4E3-4C88B185BC78/0/IWMhandbooktext.pdf.

Dennis, B. 2002. Allee effects in stochastic populations. Oikos 96(3):389-401.

Ellison, A. M., and J. N. Parker. 2002. Seed dispersal and seedling establishment of Sarracenia purpurea (Sarraceniaceae). American Journal of Botany 89(6):1024-1026.
Fenton, A., R. L. Gwynn, A. Gupta, R. Norman, J. P. Fairbairn, and P. J. Hudson. 2002. Optimal application strategies for entomopathogenic nematodes: integrating theoretical and empirical approaches. Journal of Applied Ecology 39 (3):481-492.

Fenton, A., and S. A. Rands. 2004. Optimal parasite infection strategies: a state-dependent approach. International Journal for Parasitology 34 (7):813-821.

Foley, M. E. 2004. Leafy spurge (Euphorbia esula) seed dormancy. Weed Science 52(1):74-77.

Grapputo, A., S. Boman, L. Lindström, A. Lyytinen, and J. Mappes. 2005. The voyage of an invasive species across continents: genetic diversity of North American and European Colorado potato beetle populations. Molecular Ecology 14 (14):4207-4219.

Harris, P., P. H. Dunn, D. Schroeder, and R. Vonmoos. 1985. Biological control of leafy spurge in North America. Pages 79-92 in A. K. Watson, editor. Leafy spurge. Monograph Number 3. Weed Science Society of America, Champaign, Illinois, USA.

He, H. S., and D. J. Mladenoff. 1999. The effects of seed dispersal on the simulation of long-term forest landscape change. Ecosystems 2(4):308-319.

Hoffmeister, T. S., L. E. M. Vet, A. Biere, K. Holsinger, and J. Filser. 2005. Ecological and evolutionary consequences of biological invasion and habitat fragmentation. Ecosystems 8(6):657-667.

Kirby, D. R., R. B. Carlson, K. D. Krabbenhoft, D. Mundal, and M. M. Kirby. 2000. Biological control of leafy spurge with introduced flea beetles (Aphthona spp.). Journal of Range Management 53 (3):305-308.

Lajuenesse, S., R. L. Sheley, R. Lym, D. Cooksey, C. Duncan, J. Lacy, N. Rees, and M. Ferrell. 1994. Leafy spurge: biology, ecology and management. Extension Bulletin EB 34. Montana State University, Bozeman, Montana, USA.

Leistritz, F. L., F. Thompson, and J. A. Leitch. 1992. Economic impact of leafy spurge (Euphorbia esula) in North Dakota. Weed Science 40:275-280. 
Leitch, J. A., L. Leistritz, and D. Bangsund. 1994. Economic effect of leafy spurge in the upper Great Plains: methods, models and results. Agricultural Economics Report 316, Agricultural Experiment Station, North Dakota University, Fargo, North Dakota, USA.

Leung, B., J. M. Drake, and D. M. Lodge. 2004. Predicting invasions: propagule pressure and the gravity of Allee effects. Ecology 85(6):1651-1660.

Leung, B., D. M. Lodge, D. Finnoff, J. F. Shogren, M. A. Lewis, and G. Lamberti. 2002. An ounce of prevention or a pound of cure: bioeconomic risk analysis of invasive species. Proceedings of the Royal Society of London B: Biological Sciences 269 (1508):2407-2413.

Lym, R. G. 2005. Integration of biological control agents with other weed management technologies: successes from the leafy spurge (Euphorbia esula) IPM program. Biological Control 35(3):366-375.

Lym, R. G., C. G. Messersmith, and R. Zollinger. 1993. Leafy spurge identification and control. North Dakota State University Extension Service Publication W-765. North Dakota State University, Fargo, North Dakota, USA.

Lym, R. G., and J. A. Nelson. 2000. Biological control of leafy spurge (Euphorbia esula) with Aphthona spp. along railroad right-of-ways. Weed Technology 14(3):642-646.

Lym, R. G., and J. A. Nelson. 2002. Integration of Aphthona spp. flea beetles and herbicides for leafy spurge (Euphorbia esula) control. Weed Science 50 (6):812-819.

Mack, R. N., D. Simberloff, W. M. Lonsdale, H. Evans, M. Clout, and F. A. Bazzaz. 2000. Biotic invasions: causes, epidemiology, global consequences, and control. Ecological Applications 10(3):689-710.

McCarthy, M. A., H. P. Possingham, and A. M. Gill. 2001. Using stochastic dynamic programming to determine optimal fire management for Banksia ornata. Journal of Applied Ecology 38(3):585-592.

McClay, A. S., D. E. Cole, P. Harris, and C. J. Richardson. 1995. Biological control of leafy spurge in Alberta: progress and prospects. Alberta Environmental Centre, Vegreville, Canada.
Nehrbass, N., E. Winkler, J. Pergl, I. Perglová, and P. Pyšek. 2006. Empirical and virtual investigation of the population dynamics of an alien plant under the constraints of local carrying capacity: Heracleum mantegazzianum in the Czech Republic. Perspectives in Plant Ecology, Evolution and Systematics 7(4):253-262.

North Dakota Department of Agriculture. 2005. 2005 noxious weed survey: reported acres. North Dakota Department of Agriculture, Bismarck, North Dakota, USA. [online] URL: http://www.agd epartment.com/Programs/Plant/NoxiousWeedSurveys. $\underline{\text { htm. }}$

Pandey, S., and R. W. Medd. 1991. A stochastic dynamic programming framework for weed control decision making: an application to Avena fatua $\mathrm{L}$. Agricultural Economics 6(2):115-128.

Pausas, J. G., F. Lloret, and M. Vilà. 2006. Simulating the effects of different disturbance regimes on Cortaderia selloana invasion. Biological Conservation 128(1):128-135.

Pimentel, D., L. Lach, R. Zuniga, and D. Morrison. 2000. Environmental and economic costs of nonindigenous species in the United States. Bioscience 50(1):53-65.

Raimundo, R. L. G., R. L. Fonseca, R. SchachettiPereira, A. T. Peterson, and T. M. Lewinsohn. 2007. Native and exotic distributions of siamweed (Chromolaena odorata) modeled using the genetic algorithm for rule-set production. Weed Science 55 (1):41-48.

Rinella, M. J., and R. L. Sheley. 2005. A model for predicting invasive weed and grass dynamics. I. Model development. Weed Science 53(5):586-593.

Sakai, A. K., F. W. Allendorf, J. S. Holt, D. M. Lodge, J. Molofsky, K. A. With, S. Baughman, R. J. Cabin, J. E. Cohen, N. C. Ellstrand, D. E. McCauley, P. O'Neil, I. M. Parker, J. N. Thompson, and S. G. Weller. 2001. The population biology of invasive species. Annual Review of Ecology and Systematics 32:305-332.

Scheiman, D. M., E. K. Bollinger, and D. H. Johnson. 2003. Effects of leafy spurge infestation on grassland birds. Journal of Wildlife Management 67(1):115-121. 
Selleck, G. W., R. T. Coupland, and C. Frankton. 1962. Leafy spurge in Saskatchewan. Ecological Monographs 32(1):1-29.

Sells, J. E. 1995. Optimising weed management using stochastic dynamic programming to take account of uncertain herbicide performance. Agricultural Systems 48(3):271-296.

Shastri, Y., and U. Diwekar. 2006. Sustainable ecosystem management using optimal control theory: part 2 (stochastic systems). Journal of Theoretical Biology 241(3):522-532.

Shea, K., and P. Chesson. 2002. Community ecology theory as a framework for biological invasions. Trends in Ecology and Evolution 17 (4):170-176.

Shea, K., and H. P. Possingham. 2000. Optimal release strategies for biological control agents: an application of stochastic dynamic programming to population management. Journal of Applied Ecology 37(1):77-86.

Stromme, K., D. E. Cole, A. S. McClay, C. J. Richardson, and J. de Valois. 1996. Biocontrol of leafy spurge with Aphthona nigriscutis in Alberta: the Beverly Bridge Site. Pages 26-27 in Proceedings of the Great Plains Agriculture Council GPC-14, Leafy Spurge Control in the Great Plains. Manitoba Agriculture, Brandon, Canada.

Taylor, C. M., and A. Hastings. 2004. Finding optimal control strategies for invasive species: a density-structured model for Spartina alterniflora. Journal of Applied Ecology 41(6):1049-1057.

United States Department of AgricultureAgricultural Research Service TEAM Leafy Spurge. 2002. Biological control of leafy spurge. United States Department of AgricultureAgricultural Research Service Northern Plains Agricultural Laboratory, Sidney, Montana, USA. Available online at: http://www.team.ars.usda.gov/ biocontrolmanual.pdf.

University of Idaho Extension. 2001. Bug bombing: aerial application of flea beetles for leafy spurge management. University of Idaho Cooperative Extension System, Arco, Idaho, USA. Available online at: http://www.extension.uidaho.edu/ impacts/Pdf 00/bugbombing00.pdf.
Vitousek, P. M., C. M. D’Antonio, L. L. Loope, and R. Westbrooks. 1996. Biological invasions as global environmental change. American Scientist $\mathbf{8 4}$ (5):468-478.

White, D. J., E. Haber, and C. Keddy. 1993. Invasive plants of natural habitats in Canada: an integrated review of wetland and upland species and legislation governing their control. Canadian Wildlife Service, Ottawa, Canada. Available online at: http://www.cws-scf.ec.gc.ca/publications/inv/index e. cfm.

Winkler, E., and T. Heinken. 2007. Spread of an ant-dispersed annual herb: an individual-based simulation study on population development of Melampyrum pratense L. Ecological Modelling 203 (3-4):424-438. 
Appendix 1. Further details of the SDP model

Please click here to download file 'appendix1.pdf'. 